\title{
Sobre o canto XXVI do Inferno
}

Raphael Salomão Khede ${ }^{a}$

\section{Resumo \\ $O$ artigo se propõe a analisar estilisticamente o canto XXVI do Inferno, evidenciando elementos estruturais da obra-prima de Dante Alighieri. \\ Palavras-chave: Dante Alighieri, Divina Commedia, poesia italiana, análise estilística.}

a Professor adjunto de Língua e Literatura Italiana da Universidade Estadual do Rio de Janeiro (UERJ), raphaelsalomao@hotmail.com 
A escolha da análise do canto XXVI do Inferno de Dante Alighieri (1265-1321) se deve a um terceto que está gravado na memória coletiva dos italianos: "considerate la vostra semenza / fatti non foste a viver come bruti / ma per seguir virtute e canoscenza". Nossa proposta será analisar esse canto através da paráfrase, concentrando nossa atenção sobre três aspectos recorrentes no canto e na obra principal do poeta italiano, a Divina Commedia: 1) a referência ao mundo histórico-terreno; 2) a intertextualidade e as alusões mitológicas, bíblicas e científicas; 3) o relacionamento "pré-humanista" de Dante com o mundo clássico (o qual iria "renascer" de forma filológica, logo em seguida, a partir da recuperação de manuscritos por parte de outros dois grandes do Trecento italiano, Petrarca e Boccaccio).

Antes de nos adentrarmos especificamente na análise do canto, introduziremos brevemente alguns elementos fundamentais inerentes ao poema dantesco. Em relação à transmissão da Divina Commedia, cuja primeira edição impressa foi a de 1472, existem mais de 600 códigos, porém nenhum autógrafo, assim como não existem autógrafos de outras obras do autor. Dante dividiu e publicou em três partes separadas o seu poema: o Inferno foi iniciado provavelmente a partir de 1307, sendo que os dois primeiros cânticos (Inferno e Purgatório) foram divulgados a partir de 1313-1314 e o último, o Paraíso, foi publicado, na sua totalidade, póstumo (CONTINI, 2013, p. 361-368). O poeta se referiu a sua obra como "comedia" no verso 128 do canto XVI e no verso 2 do canto XXI, sempre no Inferno. Na importantíssima carta a Cangrande della Scala (ALIGHIERI, 2014, p. 1494-1521), através da qual o poeta dedica ao comandante de Verona o terceiro cântico (o Paraíso), Dante explica o título de sua obra ("comedia vero inchoat asperitatem alicuius rei, sed eius materia prospere terminatur"), a língua por ele utilizada ("ad modum loquendi, remissus est modus et humilis, quia locutio vulgaris in qua et muliercule communicant") e a dupla possibilidade de interpretação, literal e alegórica.

A escolha da palavra "comédia" como título para a obra ainda suscita discussões entre os especialistas e estaria relacionada, segundo a carta, a dois fatores: o primeiro é de caráter estrutural, a partir do momento em que a tragédia é o gênero canonizado no mundo clássico, cujo enredo se inicia 
de forma positiva e conclui de forma negativa; na comédia, ao contrário, a história começa "mal" e termina "bem": a obra de Dante seria uma "comédia" por se iniciar "mal" no Inferno e terminar "bem" no Paraíso. O segundo motivo para a explicação do título é de caráter linguístico-estilístico: segundo a retórica antiga, reatualizada pelas artes dictandi medievais (ALBANESE, 2014, p. 1595-1621), o nível estilístico de uma obra deveria acompanhar a importância do argumento tratado; segundo tal concepção, os estilos concebidos a partir da matéria retratada eram três, com base no tríplice modelo virgiliano: trágico ou sermo sublimis (segundo o modelo da Eneida), elegíaco (seguindo as Bucólicas) e cômico ou sermo humilis (com base nas Geórgicas). O trágico era o grande estilo da épica e da tragédia, ao retratar os deuses e os heróis mitológicos e nobres, tema fundamental da literatura clássica; o elegíaco era o estilo da poesia lírica e dos temas bucólicos, e o cômico era o estilo do cotidiano, do popular, do realístico (AUERBACH, 2007, p. 41-43). A partir do momento em que Dante usa a língua que era chamada de "vulgar", e não o latim (língua da cultura e das chancelarias na época), para escrever seu "poema sagrado" "poema sacro" como o poeta o define em dois cantos do Paraíso: no verso 62 do XXIII e no verso 1 do XXV), não utiliza o estilo trágico da Eneida de Virgílio e sim um estilo e uma língua mais "humildes" que lhe permitem retratar não somente o universal (o mito e a tradição clássica e bíblica), mas também o contingente (a realidade histórica e contemporânea, os acontecimentos políticos da crônica de Florença e de outras cidades italianas da época). Portanto, segundo esse ponto vista, a sua obra não é uma "tragédia" e sim uma "comédia". Sempre em relação ao título, o adjetivo "divina" não foi originalmente usado por Dante e sim acrescentado à edição de 1555, organizada por Ludovico Dolce.

A Commedia narra a viagem ultraterrena de Dante, do Inferno até a contemplação de Deus. $O$ tema da viagem como busca da própria identidade e como uma sucessão de experiências, como itinerário de aperfeiçoamento e expiação, era frequente na literatura medieval, especificamente na literatura cavalheiresca (por exemplo no Perceval de Chrétien de Troyes), além de representar uma prática religiosa comum na época de Dante, como no caso da peregrinação (SEGRE, 2014, p. 917-945). Lembramos também que a descida aos ínferos já havia 
sido realizada por Enéias (no Canto VI da Eneida) e por São Paulo, como citado nos versos 13-30 do II canto do Inferno, além de ser um motivo recorrente nos textos sagrados medievais, nas lendas célticas e no monaquismo irlandês (Ibidem). Na Divina Commedia, como veremos detalhadamente, transitamos entre a interpretação teológica e a interpretação histórica da realidade, sendo que a segunda depende e é explicada pela primeira. Por todo o poema sagrado, os procedimentos lógicos da escolástica sustentam a robusta estrutura arquitetônicointelectual da obra: circulamos rapidamente do contingente ao universal: de um lado o mundo historicamente corrompido de Florença, do ponto de vista moral e político (sendo que as duas esferas coincidem no poema de Dante), e do outro o mundo eterno, justo e divino do Empíreo, sede de Deus, que tudo comanda e ordena. A obra é percorrida por uma fé firme nas estruturas divinas que regem o mundo físico e moral, assim como o sentido vivo da realidade imperfeita e contingente da vida histórica. Dante, nesse sentido, simboliza duas dimensões distintas, porém unificadas pelo "eu" que percorre toda a sua produção e cujo destino é "único e irrepetível"1 (SANTAGATA, 2011, p. CXXII): ele representa o indivíduo histórico e ao mesmo tempo é o representante universal e exemplar da humanidade, e sua viagem, vivenciada por Dante-personagem no passado e descrita no presente pelo Dante-narrador em primeira pessoa, se realiza como renovação espiritual e condenação da decadência eclesiástica. Essa viagem, que se configura como uma espécie de síntese poética e sistemática de toda a realidade (literária, teológica, científica e histórica), com a mesma visão polissêmica das parábolas da Bíblia, foi conduzida através de três etapas distintas segundo o valor simbólico do número 3, o qual representa a trindade do Espírito Santo. A Commedia é dividida, como se sabe, em três cânticos (cantiche), Inferno, Purgatório e Paraíso, divididos por sua vez em 33 cantos. O Inferno possui 34 cantos porque o primeiro representa uma espécie de introdução. A solução métrica adotada é o terceto com versos hendecassílabos em rima, a chamada terza rima ou rima dantesca que funciona da seguinte maneira: com a

${ }^{1}$ Cf. Purgatório, I, 130132 (Venimmo poi in sul lito diserto, / che mai non vide navicar sue acque / omo, che di tornar sia poscia esperto). exceção da primeira e da última rima de cada canto, cada rima se repete três vezes. O número 9 também é importante como múltiplo de 3: 9 são os círculos no Inferno, 9 partes tem o Purgatório, 9 céus o Paraíso (SAPEGNO, 1979, p. 57-68). Toda 
${ }^{2}$ Cf. Paraíso, XXXIII, 142 (A l'alta fantasia qui mancò possa).

3 No ensaio Il canto XXVIII del "Paradiso", publicado em 1968, ofilólogo italiano afirma: "Amore, in altre parole, ha valore euristico rispetto alla conoscenza" (CONTINI, 2001, p. 199).

${ }^{4}$ Essa distinção paradigmática entre "língua natural" e "língua artificial" foi atualizada por Graziadio Isaia Ascoli, o qual, no famoso Proemio, distinguiu, no âmbito da discussão no século XIX sobre a "qu estão da língua", entre uma realidade "instintiva" e outra "reflexiva" da língua (2008, p. 24). a Commedia é percorrida por visões, por êxtases e por um profundo misticismo. O mundo terreno-histórico é profecia ou "figura" de uma parte da realidade divina que se atualizará no futuro. Ao homem abandonado à confusão terrena virá como ajuda a beatitude em forma de salvação. Os guias de Dante durante a viagem também são três: o poeta inicialmente é acompanhado por Virgílio, seu modelo e seu mestre ("lo mio maestro e 'l mio autore"), poeta latino (70 a.C.-19 a.C.), autor da Eneida, poema épico que narra as ações de Enéias a partir das quais se desencadeará o nascimento de Roma, sede das duas autoridades supremas que estão corrompidas segundo Dante: a autoridade terrestre do Império e a autoridade espiritual da Igreja Católica, como esclarecido pelo poeta em seu tratado político em latim Monarchia (CROCE, 1948, p. 44-45). Virgílio, "figura" do ponto máximo que a razão humana alcançou sem o acompanhamento da benevolência divina, será o guia de Dante por todo o Inferno até o Éden, no Purgatório. Beatriz, que já havia sido mitificada no prosimetron Vita Nuova e nos poemas das Rime, acompanhará Dante até o Empíreo, no Paraíso, a partir de onde será São Bernardo seu guia até a contemplação de Deus, a qual para Dante se realizará como uma espécie de "fulguração" e de experiência inefável ${ }^{2}$. Beatriz, donna beata e bella, cuja simbologia do nome resulta evidente já a partir de sua raiz grega bíos, é a mulher-personagem amada por Dante-personagem e que alegoricamente é fonte de vida, a encarnação da verdade divina, a benevolência ("grazia" em italiano). Segundo Contini, o Amor na Commedia possui um valor heurístico em relação à Ciência, ou seja, é o "amor" (Beatriz) que leva ao "conhecimento", , como resulta evidente no Inferno, canto I, versos 39-40 ("quando l'amor divino / mosse di prima quelle cose belle"), no Inferno II, 72 ("amor mi mosse, che mi fa parlare") e no Paraíso, no último canto (XXXIII) e verso da obra, o 145 ("l'amor che move il sole e l'altre stelle").

No De vulgari eloquentia, primeiro tratado sobre a "questão da língua" na Itália, escrito em latim para um público de especialistas, Dante faz a distinção entre locutio vulgaris e locutio artificialis ${ }^{4}$. A primeira é o "vulgar", língua falada por todos desde quando nascemos, a língua materna, que usamos instintivamente por imitação. A segunda é a língua da gramática, que correspondia na época de Dante ao latim, o qual necessita "de tempo e de estudo" para ser aprendido (cf. 
ALIGHIERI, 2011, p. 1133-1135). Nesse tratado Dante justifica o uso do vulgar para a compilação da Divina Commedia, sendo, segundo ele, a língua vulgar mais nobre do que a língua da gramática, enquanto falada por todos e porque "natural", ao passo que a outra é "artificial" ("Harum quoque duarum nobilior est vulgaris: tum quia prima fuit humano generi usitata; tum quia totus orbis ipsa perfruitur, licet in diversas prolationes et vocabula sit divisa; tum quia naturalis est nobis, cum illa potius artificialis existat"). Dante, nesse tratado, especifica também as quatro características principais que a língua literária nacional deveria ter: 1) ela deveria ser "ilustre" para "dar luz a quem a exercita"; 2) "cardinal" porque seria como um eixo (cardine) para os outros vulgares; 3 ) "áulica" porque digna de uma corte; 4) "curial" porque dotada de "curialidade", qualidade que consiste na equilibrada norma do agir e que se podia "encontrar nas cúrias mais ilustres".

Outro elemento estrutural relevante se refere à disposição geográfica, cosmológica e física dos três reinos ultraterrenos ao longo dos quais se realiza a viagem de Dante: na Commedia, como resultará evidente através da análise do canto, a representação cosmogônica é influenciada diretamente pela visão religiosa e moral que engloba toda a existência humana. A concepção do universo de Dante e da tomística à qual ele adere se baseia nas regras fixadas pelo astrônomo grego Ptolomeu do II século d.C. Segundo tal concepção rigidamente teocêntrica, a esfera terrestre está no centro do universo e em volta dela gravitam as nove esferas celestes, inseridas uma dentro da outra, sendo que a décima, o Empíreo, sede de Deus, contém todas. No centro da terra se encontra Jerusalém; o hemisfério setentrional é o único habitado e tem como limite no oriente o Ganges, na Índia, e no ocidente as colunas de Hércules, no estreito de Gibraltar. Nas profundezas da terra se encontra o Inferno, que se afunila até a sede eterna de Lúcifer no ponto mais baixo. No hemisfério meridional se eleva a montanha do Purgatório onde estão as almas dos que morreram e que foram destinados à beatitude com a condição, porém, de purificar-se preliminarmente. No topo da montanha, no ponto mais próximo à esfera celeste mais baixa, se ergue o Paraíso terrestre. A ordem das esferas celestes se baseia nos sete planetas da antiga astronomia: a Lua, Mercúrio, Vênus, o Sol, Marte, Júpiter e Saturno. O oitavo céu é o das estrelas fixas e o 
nono é o Primo mobile, invisível e cristalino, sendo o Empíreo a esfera mais veloz. No Inferno, os pecadores estão agrupados, segundo critérios de derivação aristotélico-tomística, em três categorias de pecado: incontinência, violência e fraude. Os incontinentes ocupam os primeiros seis círculos, os violentos o sétimo, os fraudulentos o oitavo, dividido em dez fossas chamadas de "Malebolge". No nono círculo se encontra Lúcifer, o qual, com suas três bocas, devora os três grandes traidores por antonomásia: Bruto e Cássio (que traíram Cesar, símbolo do Império que, para Dante, como já foi lembrado, era a suprema autoridade terrestre) e Judas (traidor de Cristo, símbolo da Igreja Católica, suprema autoridade religiosa). O Purgatório, por sua vez, se divide em nove partes: o ante-Purgatório na parte mais baixa, o Paraíso Terrestre no topo e no meio as sete cornijas, uma para cada pecado capital: soberba, inveja, ira, acídia, avareza ou prodigalidade (como antônimo), gula e luxúria (DE SANCTIS, 1996, p. 141-242).

\section{2}

Após a breve apresentação geral, podemos passar especificamente para a análise do canto XXVI, para a qual irei me basear na edição crítica publicada por Giorgio Petrocchi em 1966-1967. A tradução do canto em forma de paráfrase exerce uma função meramente crítica, pretendendo representar apenas um suporte para a análise e, em nenhum caso, uma versão em português definitiva do texto poético dantesco. Nesse canto, devemos lembrar, seremos guiados por três elementos fundamentais presentes ao longo da obra inteira: o caráter histórico da Commedia, seu aspecto enciclopédico (ou seja, sua concepção de suma de todo o saber, de thesaurus dos conhecimentos teológicos, astronômicos, históricos, filosóficos e literários) e o significado da operação de recuperação do mundo clássico-pagão realizada por Dante.

Para a análise do canto decidimos dividi-lo em cinco partes: a primeira se refere à invectiva contra Florença (entre os versos 1-12); a segunda é a representação do espaço percorrido por Dante e Virgílio (13-42); a terceira representa o diálogo entre Dante e Virgílio (43-75); a quarta é o diálogo entre Virgílio e a chama (75-90) e a quinta é o momento principal e trágico do canto: a fala de Ulisses (90-142). 
Na primeira parte, entre os versos 1-12, nos deparamos de imediato com o fator político, histórico, terreno, realístico da Commedia, segundo a célebre concepção auerbachiana. Para o filólogo alemão, com o advento do Cristianismo houve uma ruptura paradigmática no mundo cultural ocidental, a partir do momento em que a encarnação de Cristo representou a junção entre o elemento religioso-trágico (por ser filho de Deus) e o aspecto cotidiano-realístico (por ter se encarnado no filho de um carpinteiro e ter circulado entre as pessoas mais humildes). Tal mudança de paradigma determinou o fim da divisão, imposta pela retórica clássica, entre estilo trágico e estilo realístico. A partir do Cristianismo, segundo Auerbach, a "realidade histórico-cotidiana" é considerada, na cultura ocidental, não mais como motivo e tema "cômicos", e sim em toda a sua seriedade e problematização.

O canto se inicia de forma sarcástica com a invectiva contra Florença (cidade natal de Dante e da qual ele foi exilado em 1302), em contraste com o tom sério adotado pelo poeta nas invectivas contra outras cidades, como Pistoia (no canto XXV) ou Pisa (canto XXXIII). Dando continuidade à narração de sua viagem através do Inferno, Dante, dirigindo-se diretamente à Florença, afirma ironicamente que a cidade pode sentir-se satisfeita, pois seu nome é bastante citado no Inferno ("per lo "nferno tuo nome si spande"); de fato, no canto anterior, o vigésimo quinto, na sétima fossa, Dante havia acabado de encontrar cinco ladrões florentinos (vários personagens históricos florentinos circulam pelo Inferno). No sétimo verso resulta evidente o que os críticos denominaram de "significado simbólico e profético" da Commedia: após demonstrar vergonha pelo futuro da cidade (vergonha sublinhada pela aliteração: "mi ven vergogna"), o poeta diz ter sonhado (trata-se de um sonho feito de manhã, por isso "mais verdadeiro" segundo uma crença medieval ${ }^{5}$ que Florença seria derrotada em guerra por outras cidades, como Prato por exemplo. Guerra movida contra ela pela sua arrogância e por sua degeneração moral. Quanto mais o "eubiográfico" de Dante envelhecerá, afirma poeticamente o Dante-narrador, mais essa situação representará para ele um peso. Trata-se, portanto, de uma profecia de um futuro negativo para a cidade e para seu cidadão exilado, o Dante-personagem

${ }^{5}$ Cf. A. M. Chiavacci Leonardi in ALIGHIERI, 2005, p. 768. histórico. As profecias são bastante recorrentes ao longo da viagem ultraterrena do poeta, a partir do momento em que a 
viagem do "eu" ("mi ritrovai") é símbolo da viagem de toda a humanidade ("nostra"), como sublinhou Singleton, a partir da análise dos dois primeiros versos do I canto do Inferno: "Nel mezzo del cammim di nostra vita / mi ritrovai per una selva oscura".

Na segunda parte, entre os versos 13 e 42, nos deparamos com uma representação espacial, na qual podemos notar explicitamente a diferença entre Dante-personagem e Dantenarrador: na frase "allor mi dolsi e ora mi ridoglio", "dolsi" é passado (passato remoto), tempo verbal utilizado pelo narrador para se referir à viagem de Dante-personagem, e "ridoglio" é presente, tempo utilizado por Dante-narrador, o qual concluiu a viagem ultraterrena que "agora" está narrando para seus leitores. Nesse ponto do texto, há uma descrição do lugar onde Dante e Virgílio se encontram através de duas similitudes: Dante começa a narração na primeira pessoa do plural, "nós", contando como eles partiram por um caminho solitário (porque sem a presença de Deus) e rodeado por uma paisagem cheia de pedras e rochas ("rocchi de lo scoglio"; poucos versos adiante Dante usará o termo "ronchion", em português "rochedo").

Entre os versos 19 e 24 resulta evidente a conotação teológica do texto, quando Dante-narrador declara sua dor causada pela lembrança do que viu e o medo de que seu pensamento ("'ngegno") não seja acompanhado pela virtude ("virtù"); o poeta espera não desperdiçar o bem que uma "boa estrela" ("stella bona") ou "coisa melhor" ("miglior cosa", ou seja, Deus) lhe concedera. Temos aqui explicitado o significado da missão de Dante e uns dos sentidos da obra: o poeta foi escolhido milagrosamente - e Beatriz é a prova desse milagre ("venuta da cielo in terra a miracol mostrare", como a ela se refere o eu-lírico na Vita Nuova, no famoso soneto "Tanto gentile e tanto onesta pare") - pelas esferas divinas para viver e relatar à humanidade o que viu e ouviu durante sua viagem no além ("allor mi dolsi, e ora mi ridoglio, / quando drizzo la mente a ciò ch' io vidi, / e più lo 'ngegno affreno ch' $i$ ' non soglio, / perché non corra che virtù nol guidi; / sì che, se stella bona o miglior cosa / $m$ ' ha dato ' $l$ ben, ch'io stessi nol m'invidi"). Nesse trecho também retorna um conceito que já indicamos: para Dante, o intelecto ("ngegno") está submetido a um guia, a virtude ("virtù").

Nos versos 25-33 encontramos uma similitude paisagística, com traços fortemente realísticos, que poderia ser traduzida mais ou menos assim: “Tantos vagalumes vê o camponês do 
morro onde mora, no vale onde trabalha, na estação ${ }^{6}$ em que aquele $^{7}$ que clareia o mundo nos mantém menos escondida a sua face, na hora ${ }^{8}$ em que a mosca cede o lugar ao mosquito, quantas chamas refletia a oitava fossa, assim como eu a vi logo que subi no lugar através do qual podia distinguir o fundo".

Nos versos 34-42 nos deparamos com a forte intertextualidade da obra de Dante, como resulta evidente pela presença de uma segunda similitude que se refere a dois episódios bíblicos violentos. O primeiro diz respeito ao profeta Eliseu que, ao chegar à cidade de Betel, amaldiçoou alguns jovens que zombavam dele e que acabaram sendo devorados por dois ursos. O segundo episódio se refere mais uma vez a Eliseu e a Elias, o qual foi raptado por uma carroça de fogo com cavalos em chamas, os quais surgiram tão rapidamente que Eliseu pôde distinguir somente uma chama subindo para o céu como uma nuvem.

Na terceira parte, entre os versos 43-75, ocorre o diálogo entre Dante e Virgílio, no qual se percebe a recuperação do mundo clássico através do senso alegórico, como ocorrido no primeiro canto do Inferno, quando Dante se havia deparado com três feras: um leopardo, um leão e uma loba, que representam, do ponto de vista político, respectivamente, Florença, o Império e o Papado e, do ponto de vista moral, a luxúria, a soberba e a avareza. Virgílio profetizou, nesse primeiro canto do Inferno, a chegada de um cão de caça chamado de "veltro", o qual viria derrotar os vícios da loba (Igreja). Muito próximo desse valor alegórico, Auerbach (2008) assinalou a presença do conceito de "figura" na Commedia: figura, segundo o filólogo alemão, seria uma espécie de profecia divina que se completará no futuro, ou seja, se trata da antecipação de uma ideia, de um conceito ou de um fato histórico ligado a um personagem realmente existido. Virgílio, por exemplo, representa a razão humana porque antecipou em sua obra um acontecimento futuro determinante como o surgimento de Roma, além de ter sido modelo de estilo para Dante, como resulta, mais uma vez, da leitura do primeiro canto do Inferno. Do mesmo modo, no canto de Ulisses que estamos comentando, a trajetória do herói grego

${ }^{6}$ Verão.

${ }^{7} \mathrm{O}$ sol.

${ }^{8}$ Ao anoitecer. é também avaliada através de uma interpretação alegórica: Ulisses, como veremos, é "figura" de um acontecimento interior vivenciado por Dante: "Quella fine infatti è una figura, come tutta 
la storia di Ulisse, di una vicenda dello spirito, che Dante stesso ha vissuto" (CHIAVACCI LEONARDI, 2005, p.778).

A partir do verso 43, Dante começa a narrar seu encontro com Ulisses e Diomedes; o poeta estava observando do alto as chamas no fundo da fossa e Virgílio (designado de "duca" e "maestro mio"), percebendo a sua atenção, lhe explicou que dentro das chamas estavam os espíritos. Dante, então, lhe perguntou que tipo de fogo era aquele que parecia dividido na sua parte superior e parecia ter surgido da fogueira onde foi colocado Etéocles com seu irmão. Trata-se de mais uma referência ao mito. Os irmãos Etéocles e Polinices foram queimados no mesmo fogo. Filhos de Édipo e Jocasta, eles expulsaram o pai do trono e foram por ele amaldiçoados. Em seguida, os dois se desentenderam, iniciando uma guerra durante a qual ambos morreram e tiveram seus corpos queimados numa mesma fogueira: porém, como narra o mito, a chama se dividiu em duas partes.

Virgílio informa a Dante, dizendo-lhe que dentro da chama se encontram Ulisses e Diomedes, os quais, assim como erraram em vida, estão condenados a cumprir juntos, eternamente, a mesma pena. Virgílio explica também que dentro daquela chama eles descontam a culpa pela invenção do cavalo de Troia, o engano de Aquiles e o roubo da estátua de Palas Atena, o "Palladio".

A primeira fraude se refere à invenção do cavalo de madeira entregue aos troianos, após 10 anos de guerra, como símbolo de amizade, cavalo idealizado por Ulisses, dentro do qual estavam escondidos diversos guerreiros gregos que puderam abrir as portas da cidade para que seus companheiros a destruíssem em seguida. De Troia fugiram alguns heróis, como Enéias, o qual depois de uma longa viagem conseguiu chegar a Roma (episódio narrado na Eneida de Virgílio).

A segunda fraude se refere ao engano de Aquiles realizado por Ulisses e Diomedes. Aquiles, escondido na corte de Licomedes para não participar da guerra de Troia, foi descoberto pelos dois heróis que o convenceram com artimanha (mostrando-lhe armas para excitar seu senso guerreiro) e o conduziram para a guerra. Deidamia, filha de Licomedes, havia se apaixonado por Aquiles, pelo qual ainda sofre no Limbo, no Purgatório, onde será lembrada por Dante no canto XXII. 
${ }^{9}$ Segundo Sapegno, nesse trecho existe um sinal de reverência pelo mundo grego (dos heróis, dos mitos, dos filósofos e dos poetas) que Dante herdou de seus venerados autores latinos (CHIAVACCI LEONARDI, 2005, p. 779).

${ }^{10}$ Dante usa a expressão "alti versi" ("altos versos"), pois o estilo da Eneida correspondia ao grau retórico ilustre ou trágico.

11 A palavra "pietà" é recorrente e importante também em muitos outros cantos da Commedia e alude à pietas virgiliana revisitada pela caritas cristã, no sentido de participação à dor alheia.

${ }^{12}$ Em italiano há uma tríplice aliteração em "m": "ma misi me": quase um "gaguejar", cujo efeito fono-simbólico será aproveitado também por Petrarca no ilustre soneto de abertura do Canzoniere: "di me medesmo meco mi vergogno").
A terceira fraude se refere ao roubo sacrílego da estátua de Palas Atena, chamada de "Palladio", símbolo de proteção da cidade de Troia.

Após as explicações do mestre, Dante implora Virgílio, com insistência marcada pelo poliptoto (a palavra "priego" é repetida duas vezes: uma com função de verbo e outra com função de nome) e pela figura etimológica ("riprego"), para que faça com que a chama se aproxime. Virgílio lhe responde dizendo que o seu pedido é louvável, porém pede para que Dante permaneça em silêncio e que seja ele a falar, porque os espíritos são gregos e poderiam não entender a língua de Dante e, por isso, considerá-lo bárbaro ${ }^{9}$. Virgílio, ao contrário, por ter exaltado as peripécias de Ulisses na Eneida, acredita que não será ignorado ou desprezado por eles.

Na quarta parte, entre os versos 75-90, Virgílio se dirige à chama dupla (a aliteração reforça a dualidade: "due dentro ad un foco") que tinha se aproximado dos dois poetas: se obteve algum mérito, afirma o poeta latino, pelo que escreveu ${ }^{10}$ (" $s$ ' io meritai", conceito valorizado pela anáfora), pede para que uma das chamas lhe conte do naufrágio e onde foi concluir a própria vida. Portanto, Virgílio está se dirigindo claramente a Ulisses, o qual, após o naufrágio, começara sua viagem de retorno para Ítaca, sua terra natal. A ponta ("corno") maior da chama começa a se mexer como se o vento a tivesse agitado, movimentando sua parte superior como se fosse uma língua falando.

Na quinta parte, a maior e última, entre os versos 90-142, ocorre o famoso discurso de Ulisses. Ele começa a contar de quando foi prisioneiro por mais de um ano da maga Circe que transformava em porcos os navegantes que se apaixonavam por ela; Enéias nomeou em seguida essa localidade, nas proximidades do Monte Circeo, de Gaeta, cidade na região Lácio. Portanto, depois de ter partido da corte de Circe, Ulisses afirma que nem a doçura do filho (Telêmaco), nem a piedade ${ }^{11}$ pelo velho pai (Laerte), nem o amor devido a sua esposa (Penélope) puderam vencer o desejo (l'ardore) que, declara Ulisses, "eu tive de conhecer o mundo, os vícios e a virtude dos homens; ao contrário, me embarquei ${ }^{12} \mathrm{em}$ alto mar com os meus companheiros que não me abandonaram".

Ulisses passou pela Sardenha, pelo litoral de um lado da Espanha e do outro de Marrocos; ele e seus companheiros haviam se tornado "velhos e cansados" quando alcançaram o 
estreito de Gibraltar, onde se erguiam, segundo o mito, as duas colunas de Hércules, uma do lado da Europa, em Calpe, e a outra na África, em Abila, representando o limite ocidental do mundo conhecido: a partir dali, era proibido aos navegantes o caminho e a entrada no oceano Atlântico.

É necessário interrompermos a viagem de Ulisses, para dedicarmos rapidamente nossa atenção a um adjetivo usado por Dante. Dante usa para Laerte, o pai de Ulisses, a palavra "vecchio": trata-se, nesse caso, de um exemplo típico do "plurilinguismo" adotado na Commedia, a partir do momento em que o poeta utiliza três formas diferentes, inclusive com níveis estilísticos distintos, para o mesmo conceito ao longo de sua obra. No caso que estamos examinando, Dante utiliza a palavra "vecchio" (que entrou para a língua comum italiana), enquanto no Purgatório (canto I) para Catão usa o termo "veglio" (que permaneceu como termo do campo poético), e no Paraíso (canto XXXI) para São Bernardo ele usa o fortemente latinizado "sene". Como sinalizado por Contini (1992), no ensaio Preliminari sulla lingua del Petrarca, em contraste com o "monolinguismo" do Canzoniere de Petrarca, o estilo de Dante se caracteriza como uma mescla de vários registros linguísticos e de vários estilos, do florentino contemporâneo a outras formas de toscano, da língua da escolástica (como resulta evidente pelo uso intenso de paralelismos e de silogismos) à criação de neologismos, ao uso de palavras provenientes do latim, da língua d'oc e da língua d'oil e de vários regionalismos, através de um amplo trabalho de contaminatio. No mesmo ensaio, Contini evidencia outras duas diferenças fundamentais entre os dois grandes poetas: o interesse teorético de Dante (sua "ansiedade de justificar$\mathrm{se}^{\prime \prime}$ ) e seu incessante experimentalismo em contraposição ao meticuloso trabalho de Petrarca o qual corrigiu e reescreveu em nove redações, ao longo de quase quarenta anos, seus Rerum vulgarium fragmenta.

Mas retornando à viagem de Ulisses, ele e seus companheiros passam por Sevilha de um lado e por Ceuta do outro e, aqui, Ulisses profere o famoso discurso ao seu fiel e pequeno grupo ("compagna picciola") de companheiros de navegação: "Oh irmãos, vós que chegastes após cem mil perigos ao Ocidente, nos últimos dias de nossa vida ("a questa tanto piccola vigilia / de' nostri sensi ch'è del rimanente"), não queirais renunciar à experiência do mundo desconhecido 
("mondo sanza gente"), ao seguir o sol. Considerais a vossa origem, feitos não fostes para viver como bichos ("bruti"), mas para seguir virtude e conhecimento".

Depois de incitar seus companheiros, Ulisses diz que os deixou tão determinados que quase não teria conseguido convencê-los de desistir, caso tivesse tentado, como ressaltado pela aliteração ("che a pena poscia li avrei ritenuti").

Sempre continuando pelo lado esquerdo em direção ao oeste, os navegantes empreendem o que Ulisses chama de "louca viagem" ("folle volo") $)^{13}$.

Entre os versos 127-135 há uma das típicas descrições astronômicas da Commedia, presente no discurso proferido por Ulisses, o qual narra que, durante a noite, dava para ver todas as estrelas do polo antártico ("l'altro polo"), enquanto o polo ártico ("nostro") estava tão baixo que não conseguia se elevar acima da linha do horizonte ("marin suolo"). Eles já estavam viajando com dificuldades ("alto passo") havia cinco meses ("desde que o sol havia dado cinco voltas em torno da lua"), quando então avistaram uma montanha muito alta e escura: a montanha do Purgatório que, em seguida, será alcançada também por Dante, no início de sua viagem pelo Purgatório: "Per correr migliori acque alza le vele / omai la navicella del mio ingegno, / che lascia dietro a sé mar sì crudele".

"Ficamos felizes", narra Ulisses, "mas repentinamente um vento se abateu sobre a proa da embarcação, fazendo-a rodar por quatro vezes até que a popa ficou para cima e a proa para baixo e o mar se fechou sobre nós". Ulisses e seus companheiros foram sugados pelo abismo marítimo.

A partir da leitura do canto, resultam evidentes: a visão histórico-política de Dante (no caso da sua invectiva contra Florença), o caráter enciclopédico da Commedia, repleta de citações de episódios bíblicos e mitológicos, e o ponto crucial e mais complexo do canto, a relação estabelecida por Dante com o mundo clássico. Na tradição latina, existiam versões

13 "Folle", ou seja, "louco" é um adjetivo que será utilizado de novo por Dante para Ulisses no canto XXVII do Paraíso, versos 82-3. diferentes da morte do herói grego. Dante se refere seja às culpas cometidas por Ulisses, descritas na Ilíada e na Eneida, seja à versão da Odisseia de seu "fim oceânico" (CHIAVACCI LEONARDI, 2005, p. 776). Ulisses foi posto no Inferno como 
14 "[Ulisse] è una parte di Dante stesso, cioè dell'anelito al grande, che la riverenza religiosa e l'umiltà cristiana potevano in lui infrenare, ma non distruggere. Donde la figura di quest'Ulisse dantesco, peccaminoso ma di sublime peccato, eroe tragico, maggiore forse di quel che fu mai nell'epos e nella tragedia greca". conselheiro fraudatório ("consigliere fraudolento"), pela sua famosa astúcia que se tornou contra ele mesmo. Sua inteligência e sua coragem não foram acompanhadas por uma finalidade moral e por esse motivo se tornou culpado de ter ultrapassado os limites impostos aos homens.

O canto XXVI, assim como o V, no caso do célebre episódio de Paolo e Francesca, apresenta ao leitor o momento decisivo da vida de Ulisses, o qual "se perdeu" ("perduto" é o adjetivo usado por Dante, que simboliza a "perdição" do homem que chegou a desafiar Deus). A parte final do canto, solene e trágica, suscita um problema crítico ainda discutido: Ulisses teve culpa e o naufrágio foi uma punição divina para a sua transgressão, ou foi um herói magnânimo do conhecimento, o qual não pôde alcançar sua meta somente porque pagão e, por isso, privado da fé que permite o conhecimento das "realidades divinas"? A grandeza do canto está exatamente na ambiguidade, na polissemia, diríamos, que deixa em aberto uma dúplice interpretação: ou tratou-se de uma grandeza sem sorte ou de um pecado de v̋øpıs, de excesso, de soberba.

Para Bruno Nardi (1942, p. 89-99), o herói grego representa a prevaricação do intelecto humano que deseja alcançar o "infinito" ou as "últimas realidades" manchando-se, desse jeito, da culpa análoga cometida por Adão.

Se toda a primeira parte do canto é centrada explicitamente na história pessoal de Dante e serve como proêmio para o episódio de Ulisses, do mesmo modo, no episódio do herói grego, Dante, segundo alguns críticos, estaria representando uma parte de si mesmo. Para Benedetto Croce (1948, p. 92), Ulisses, punido por uma força misteriosa e religiosa da natureza, sob ordem divina, é "uma parte de Dante, ou seja, da propensão à grandeza que a reverência religiosa e a humildade cristã podiam desacelerar nele, mas não diminuir. Daí a figura desse Ulisses dantesco, pecador mas de um pecado sublime, herói trágico, maior talvez de quanto tenha sido na épica e na tragédia grega". ${ }^{14}$

Para Chiavacci Leonardi, quem atualiza, de certa forma, a linha interpretativa de Croce nesse passo, a história de Ulisses é "figura" de um "acontecimento interior" vivenciado por Dante, ou melhor, na voz de Ulisses ecoa a voz de Dante: aquele homem que parte com ardor para o "mar misterioso do conhecimento", consciente da dignidade suprema que 
"Com' altrui piacque" aparece no verso 141 do canto XXVI do Inferno e no verso 133 do canto I do Purgatório e indica a diferença das duas ações. distingue o homem dos outros animais ("fatti non foste a viver como bruti, / ma per seguir virtute e canoscenza"), é Ulisses e Dante ao mesmo tempo. A identificação, porém, não é completa, pois existe uma diferença grande entre os dois personagens, como resulta evidente da leitura do canto I do Purgatório, no qual Dante, aludindo fortemente ao canto XXVI do Inferno (utiliza as mesmas palavras ${ }^{15}$ ), mostra o contraste entre a ação de Ulisses e a sua. Dante foi escolhido por Deus ("com' altrui piacque") "para passar por um litoral que nunca viu navegar pelas suas águas alguém que tenha sido capaz (esperto) de retornar". Sua missão, única e exemplar, será retornar entre os mortais para contar o que presenciou. Por sua vez, Ulisses, desacompanhado da fé, desejou se tornar conhecedor ("esperto") dos vícios e dos valores humanos e, por vontade divina ("com'altrui piacque"), acabou levando seus companheiros ao naufrágio: "infin che 'l mar fu sovra noi richiuso".

\section{REFERÊNCIAS}

ALBANESE, Gabriella. Introduzione (Egloge). In: ALIGHIERI, Dante. Opere, $\mathrm{II}^{\circ}$ volume (Convivio, Monarchia, Epistole, Egloge). Organização de Marco Santagata; colaboração de Gianfranco Fioravanti, Claudio Giunta, Diego Quaglioni, Claudio Villa, Gabriella Albanese. Milão: Mondadori, 2014. p. 1595-1621.

ALIGHIERI, Dante. La Divina Commedia. Comentário de Giuseppe Villaroel; revisão do comentário de Guido Davico Bonino e Carla Poma; ensaio introdutório de Eugenio Montale. Milão: Mondadori, 1991.

ALIGHIERI, Dante. Inferno. Organização, introdução e notas de Anna Maria Chiavacci Leonardi. Milão: Mondadori, 2005 (1991).

ALIGHIERI, Dante. Purgatorio. Organização, introdução e notas de Anna Maria Chiavacci Leonardi. Milão: Mondadori, 2005 (1994).

ALIGHIERI, Dante. Paradiso. Organização, introdução e notas de Anna Maria Chiavacci Leonardi. Milão: Mondadori, 2005 (1994).

ALIGHIERI, Dante. Vita nuova. Introdução e organização de Manuela Colombo; prefácio de Maria Corti. Milão: Feltrinelli, 2010. 
ALIGHIERI, Dante. Opere, $\mathrm{I}^{\circ}$ volume (Rime, Vita nuova, De vulgari eloquentia). Organização e introdução de Marco Santagata; colaboração de Claudio Giunta, Guglielmo Gorni e Mirko Tavoni. Milão: Mondadori, 2011.

ALIGHIERI, Dante. Opere, II $^{\circ}$ volume (Convivio, Monarchia, Epistole, Egloghe). Organização de Marco Santagata; colaboração de Gianfranco Fioravanti, Claudio Giunta, Diego Quaglioni, Claudio Villa, Gabriella Albanese. Milão: Mondadori, 2014.

ASCOLI, Graziadio Isaia. Scritti sulla questione della lingua. Organização de Corrado Grassi; com um ensaio introdutório de Guido Lucchini. Turim: Einaudi, 2008 (1975).

AUERBACH, Erich. Lingua letteraria e pubblico nella tarda antichità latina e nel Medioevo. Tradução de Fausto Codino. Milão: Feltrinelli, 2007 (1960).

AUERBACH, Erich. Mimesis. Il realismo nella letteratura occidentale. Ensaio introdutório de Aurelio Roncaglia; tradução de Alberto Romagnoli e Hans Hinterhäuser. Turim: Einaudi, 2000 (1956). 2 v.

AUERBACH, Erich. Studi su Dante. Prefácio de Dante Della Terza; tradução de Maria Luisa De Pieri Bonino e Dante Della Terza. Milão: Feltrinelli, 2008 (1963).

CHIAVACCI LEONARDI, Anna Maria. Commento. In: ALIGHIERI, Dante. Inferno. Organização, introdução e notas de Anna Maria Chiavacci Leonardi. Milão: Mondadori, 2005 (1991). p. 759-793.

CONTINI, Gianfranco. Letteratura italiana delle origini. Milão: Rizzoli, 2013 (1976).

CONTINI, Gianfranco. Preliminari sulla lingua del Petrarca. In: PETRARCA, Francesco. Canzoniere. Turim: Einaudi, 1992. p. XXVIII-LV.

CONTINI, Gianfranco. Un'idea di Dante. Saggi danteschi. Turim: Einaudi, 2001 (1970).

CROCE, Benedetto. La poesia di Dante. Bari: Laterza, 1948 (1921).

DE SANCTIS, Francesco. Storia della letteratura italiana. Organização de Niccolò Gallo; introdução de Giorgio Ficara. Turim: Einaudi-Gallimard, 1996 (1870-71).

NARDI, Bruno. Dante e la cultura medievale. Bari: Laterza, 1942. 
SANTAGATA, Marco. Introduzione. In: ALIGHIERI, Dante. Opere, I ${ }^{\circ}$ volume (Rime, Vita nuova, De vulgari eloquentia). Organização e introdução de Marco Santagata; colaboração de Claudio Giunta, Guglielmo Gorni e Mirko Tavoni. Milão: Mondadori, 2011. p. XI-CXVIII.

SAPEGNO, Natalino. Disegno storico della letteratura italiana. Florença: La Nuova Italia, 1979 (1949).

SEGRE, Cesare. Viaggi e visioni d'oltremondo sino alla Commedia di Dante. In: Opera critica. Organização de Alberto Conte e Andrea Mirabile; com um ensaio introdutório de Gian Luigi Beccaria. Milão: Mondadori, 2014. p. 917-945.

\begin{abstract}

\section{On canto XXVI of Inferno}

The goal of this paper is evaluating stylistically canto XXVI of Inferno, highlighting structural elements of Dante Alighieri's masterpiece.
\end{abstract}

Keywords: Dante Alighieri; Divina Commedia; Italian poetry; stylistic analysis. 